\title{
Great Britain
}

The May 1966 issue of the International Review described Florence Nightingale Medal presentation ceremonies in a number of countries. In other countries these ceremonies were scheduled for a later date so that it was not possible to give an account of them. This was the case in Great Britain.

We are now advised by the British Red Cross that the Medal was presented to Mrs. Mary Folke on July $21^{1}$, during a meeting of the National Society Council in London, by its Chairman, HRH the Duke of Gloucester.

We have already described Mrs. Folke's merits, her enterprising spirit and dedication which are a credit to the British Red Cross.

\section{Honduras}

On August 13, 1966, the presentation of diplomas to first-aiders of the Honduran Red Cross took place in Tegucigalpa. ${ }^{2}$

The sixteen youths awarded diplomas had just completed the elementary course in first-aid at the First-Aid Training School. This school is run by the Honduran Red Cross under the direction of Dr. Enrique Ortez Pinel. Two volunteers of the National Society have been appointed as instructors in the school.

Encouraged by success, the National Society has decided that the first-aid courses will be resumed in September at three different levels.

In addition, the first Departmental Council of the Honduran Red Cross was set up in June at Choluteca in the south of the country. The Red Cross ideal is spreading in this region in a most satisfactory manner and a new first-aid training school has just been opened there.

\footnotetext{
1 Plate. Mrs. Folke receiving the Florence Nightingale Medal in London.

2 Plate. Presentation of diplomas to first-aiders of the Honduran Red Cross.
} 